\title{
FILMES DE AMIDOS DE MANDIOCA MODIFICADOS PARA RECOBRIMENTO E CONSERVAÇÃO DE UVAS
}

\author{
Suellen Laís Vicentino, Patrícia Aparecida Floriano e Douglas Cardoso Dragunski*
}

Universidade Paranaense, Praça Mascarenhas de Moraes, 87502-210 Umuarama - PR, Brasil

Josiane Caetano

Departamento de Engenharias e Ciências Exatas, Universidade Estadual do Oeste do Paraná, 85903-000 Toledo - PR, Brasil

Recebido em 7/9/10; aceito em 15/3/11; publicado na web em 12/5/11

\begin{abstract}
FILMS OF STARCH CASSAVA TO COAT AND CONSERVATION OF GRAPES. In this article, films were produced with six types of cassava's starch mixed with gelatin and plasticized with sorbitol. These films were used in covering of grapes 'Benitaka' (Vitis vinifera L.) as biodegradable packaging. The acetylated starch film showed the best results in solubility, thickness and homogeneity, besides the less water loss the fruit, resulting in better coverage, increasing the shelf life fruits in 12 days. These results demonstrate the great potential of using films in food conservation, adding value to agricultural activity and helping to reduce non-biodegradable plastics in the environment.
\end{abstract}

Keywords: grapes; biodegradable; package.

\section{INTRODUÇÃO}

Com o aumento da população, tem surgido cada vez mais a necessidade de novos materiais para conservação de alimentos principalmente os in natura, como as frutas. Isso ocorre devido ao reduzido tempo de prateleira que muitos destes alimentos apresentam. Desta forma, a utilização de embalagens plásticas é uma das alternativas para promover um aumento neste tempo, no entanto, a maioria dos plásticos utilizados hoje causa danos ao meio ambiente e, consequentemente, à saúde humana.

Dentre os alimentos que possuem um tempo de vida de prateleira reduzido, encontra-se a uva. Uma espécie que vem se difundindo é a uva 'Benitaka', originada de mutação somática na variedade Itália. Destaca-se pelo intenso desenvolvimento da coloração rosada escura, mesmo quando ainda imatura, em qualquer época do ano. Apresenta cachos e bagas grandes, sendo sua polpa de textura crocante, com sabor neutro. ${ }^{1}$

Como se trata de um fruto perecível, estando suscetível à ocorrência de danos de diversas origens, suas perdas pós-colheita são estimadas em cerca de $27 \%$ da produção total. ${ }^{2}$ Os principais problemas pós-colheita das uvas são as podridões, a desidratação do engaço e a desgrana, causando perdas e prejudicando a qualidade do produto. $\mathrm{O}$ escurecimento das bagas e o ressecamento do engaço são desordens de natureza fisiológica, ocasionadas, quase sempre, durante o armazenamento refrigerado (AR). ${ }^{3,4}$

$\mathrm{O}$ emprego de embalagens adequadas pode reduzir a incidência desses processos fisiológicos prejudiciais à qualidade dos frutos, minimizando essas perdas, que podem comprometer o valor comercial das uvas. Dentre os materiais mais utilizado, encontra-se o polietileno de baixa densidade (PEBD), ${ }^{3}$ que é um material com excelentes propriedades de barreira, utilizado na forma de filme sobre o fruto, porém de difícil degradação, promovendo assim uma poluição ambiental causada pela sua deposição no meio ambiente. Nesse sentido, o desenvolvimento de filmes com características de embalagens biodegradáveis torna-se de grande interesse, pois além

*e-mail: dcdragunski@unipar.br de não causarem danos ao meio ambiente, preservam a qualidade dos produtos alimentícios..$^{5-8}$

Os filmes e coberturas possuem a função de inibir ou reduzir a migração de umidade, oxigênio, dióxido de carbono, lipídios, aromas, dentre outros, pois promovem barreiras semipermeáveis. Com isso, proporcionam aos alimentos um aspecto atrativo além de aumentar sua vida de prateleira. ${ }^{5,9,10}$

Os biopolímeros mais utilizados na elaboração de filmes e coberturas comestíveis são as proteínas (gelatina, caseína, ovoalbumina, glúten de trigo, zeína e proteínas miofibrilares), os polissacarídeos (amido e seus derivados, pectina, celulose e seus derivados, alginato e carragena) e os lipídios (monoglicerídeos acetilados, ácido esteárico, ceras e ésteres de ácido graxo) ou a combinação dos mesmos. ${ }^{11-13}$

Os filmes comestíveis tendo o amido como biopolímero para sua formação começam a ser estudados de forma mais intensa, sendo a fécula de mandioca selecionada como a matéria-prima mais adequada para sua elaboração, por formar películas resistentes e transparentes; são eficientes barreiras à perda de água, proporcionam bom aspecto e brilho intenso, tornando frutos e hortaliças comercialmente atrativos. ${ }^{14-16}$

A produção de filmes a partir de fécula de mandioca tem sido estudada pelo fato desse material ser facilmente encontrado, possuir baixo custo e também devido às suas propriedades filmógenas..$^{17,18}$ A obtenção do filme (película) de fécula de mandioca baseia-se no princípio da gomificação do amido, que ocorre acima de $70^{\circ} \mathrm{C}$, com excesso de água. A fécula gelatinizada que se obtém, quando resfriada, forma películas devido às suas propriedades de retrogradação. ${ }^{17,19}$ Atualmente, inúmeras alterações químicas nas cadeias amiláceas permitiram o desenvolvimento de amidos modificados que possuem características físico-químicas distintas do amido nativo, como melhor solubilidade e menor temperatura de gelatinização. ${ }^{20}$

As proteínas formam bons filmes e podem ser utilizadas em coberturas de frutas e hortaliças frescas. ${ }^{21} \mathrm{O}$ filme proteico mais utilizado é o colágeno, normalmente empregado como cobertura de carnes processadas. A conversão do colágeno em gelatina é a transformação essencial que ocorre na fabricação da mesma e envolve a hidrólise catalisada por ácido ou base. ${ }^{22} \mathrm{~A}$ gelatina desperta interesse por ser 
uma matéria-prima abundante, produzida praticamente em todo o mundo, de custo relativamente baixo e por ter excelentes propriedades funcionais e filmógenas. ${ }^{23-25}$

Geralmente os filmes obtidos de polissacarídeos como o amido são quebradiços; desta forma, tem-se a necessidade da inserção de plastificantes. Os sistemas poliméricos com plastificantes como o sorbitol promovem um aumento no comportamento elástico dos filmes, melhorando as propriedades mecânicas dos mesmos. ${ }^{26-29}$ Assim, para melhorar as propriedades físico-químicas desses materiais para aplicação como embalagens de frutas, está sendo estudada a inserção destes plastificantes nos polímeros.

O objetivo deste trabalho foi realizar a produção de filmes a partir de amido de mandioca, gelatina e sorbitol para cobertura em uvas 'Benitaka' (Vitis vinifera L.), bem como avaliar suas propriedades e verificar a eficácia desse filme como barreira contra a perda de massa nas uvas, objetivando aumentar sua vida de prateleira. A aplicação das coberturas foi realizada com a uva, pois é um fruto frágil com elevado teor de água em sua composição $(81 \%)$ e grande superfície de transpiração em relação a sua massa. Tal fruta possui alto valor comercial, sendo grande parte da sua produção voltada à exportação.

\section{PARTE EXPERIMENTAL}

Os filmes foram produzidos com amidos de mandioca acetilado AC, oxidado- OX, oxidado-acetilado - OXAC, nativo - NAT, eterificado - ET e catiônico - CAT, provenientes da Avebe Guaíra Amidos Ltda. Foi ainda utilizada gelatina incolor e sem sabor (Biotec - Reagentes Analíticos) e sorbitol (QUEEL - Química Especializada Erich Ltda).

\section{Metodologia para elaboração dos filmes}

A solução de gelatina (1) para elaboração dos filmes foi obtida hidratando-se $10 \mathrm{~g}$ de gelatina em $100 \mathrm{~mL}$ de água destilada por um período de $1 \mathrm{~h}$. Após a solução, foi aquecida em chapa aquecedora até solubilização, em seguida foi adicionado o sorbitol na proporção de $5 \%$ em relação à massa da gelatina sob agitação magnética. As suspensões dos diferentes amidos (acetilado, oxidado, acetilado-oxidado, catiônico, eterificado e nativo) foram preparadas utilizando $3 \mathrm{~g}$ de amido em $100 \mathrm{~mL}$ de água destilada e $10 \%$ de sorbitol em relação à massa do amido (2). A solução foi preparada em banho-maria a $85{ }^{\circ} \mathrm{C}$ até total gelatinização. Após o preparo das soluções, foi realizada a mistura da solução de gelatina (1) com cada tipo de amido (2) separadamente, para a formação de 6 tipos diferentes de soluções filmogênicas, relativos aos diferentes tipos de amido.

Alíquotas de $10 \mathrm{~mL}$ das soluções filmogênicas foram distribuídas em placas de teflon de $7 \mathrm{~cm}$ de diâmetro e secas em estufa a $40{ }^{\circ} \mathrm{C}$ por $48 \mathrm{~h}$, para a elaboração dos filmes. ${ }^{11}$ Esses filmes foram usados posteriormente para análises da espessura, solubilidade, análise térmica, opacidade e microscopia eletrônica de varredura.

\section{Espessura dos filmes}

A espessura dos filmes obtidos foi medida utilizando-se um micrômetro marca Mitutoyo. A espessura foi determinada como sendo a média de 5 medidas aleatórias em diferentes partes do filme.

\section{Solubilidade em água dos filmes}

A solubilidade em água dos filmes foi determinada em triplicata, sendo que amostras dos filmes foram recortadas em quadrados de $2 \mathrm{~cm}$. A porcentagem inicial da matéria seca de cada amostra foi determinada após deixar a mesma em estufa a $105{ }^{\circ} \mathrm{C}$ por $24 \mathrm{~h}$. Após a pesagem, as amostras foram imersas em recipientes com 25 $\mathrm{mL}$ de água destilada, e agitadas lenta e periodicamente por $24 \mathrm{~h}$.
Após esse período, as amostras foram removidas e secas $\left(105{ }^{\circ} \mathrm{C}\right.$ por $24 \mathrm{~h}$ ), para determinação da massa da matéria seca que não se dissolveu em água. ${ }^{11}$

\section{Análise térmica e opacidade dos filmes}

As medidas para determinação da temperatura de transição vítrea $(\mathrm{Tg})$ e temperatura de degradação dos filmes foram realizadas utilizando o aparelho de calorimetria exploratória diferencial (DSC) e análise termogravimétrica (TGA), respectivamente. As curvas de TGA foram realizadas utilizando um equipamento Shimadzu TGA-50, cadinho de platina, atmosfera dinâmica de nitrogênio, com velocidade do fluxo de $50 \mathrm{~mL} / \mathrm{min}$, taxa de aquecimento de $10^{\circ} \mathrm{C} /$ min e temperatura variando de 25 até $800{ }^{\circ} \mathrm{C}$. As análises de DSC foram realizadas utilizando um equipamento Shimadzu DSC-50, "panela" de alumínio tampada, atmosfera dinâmica de nitrogênio com um fluxo de $20 \mathrm{~mL} / \mathrm{min}$. Foi realizada uma primeira corrida de 25 até $120^{\circ} \mathrm{C}$, a fim de ambientar termicamente a amostra, com uma taxa de aquecimento de $20^{\circ} \mathrm{C} / \mathrm{min}$, diferentemente, da segunda e da terceira corrida, as quais foram realizadas com $10^{\circ} \mathrm{C} / \mathrm{min}$, variandose a temperatura de -100 até $140^{\circ} \mathrm{C}$, para se obter a temperatura de transição vítrea das amostras.

A opacidade dos filmes foi determinada pela análise em espectrofotômetro UV-vis do tipo UV-1650.PC Shimadzu, no qual os filmes foram fixados no orifício de passagem da luz UV-vis, para se obter a transmitância do filme na região do visível.

\section{Microscopia eletrônica de varredura (MEV)}

Por intermédio da microscopia eletrônica de varredura (MEV), pode-se observar a morfologia do filme, sua orientação e as possíveis mudanças realizadas. A morfologia das amostras de filmes foi analisada em um microscópio eletrônico de varredura digital marca Leo modelo 440. Os filmes foram colocados sobre uma fita adesiva de carbono, no porta-amostra de alumínio e recobertas com ouro, com espessura de recobrimento de $20 \mathrm{~nm}$. A corrente do feixe utilizado foi de $1 \mathrm{pA}$ e a potência do feixe de $15 \mathrm{KV}$. Além disso, os filmes foram previamente secos em estufa à $40{ }^{\circ} \mathrm{C}$ antes de serem fixados no porta-amostra.

\section{Cobertura das uvas 'Benitaka'}

Antes dos cachos das uvas receberem as coberturas dos filmes, foram imersos durante 30 min em uma solução de água e hipoclorito $(0,01 \%)$. Após esse período foram retirados da solução e colocados em bancadas para a secagem completa em temperatura ambiente. Após secos e higienizados foram divididos em 7 lotes contendo 3 cachos de uvas cada. Cada um dos lotes foi imerso em uma solução filmogênica diferente ( 6 tipos de amido) e um deles (controle) imerso em água destilada todos por um período de $1 \mathrm{~min}$. Em seguida, os cachos foram pendurados e deixados para secar em temperatura ambiente por $24 \mathrm{~h}^{11}$

\section{Perda de massa das uvas}

Os cachos das uvas foram armazenados sob temperatura de refrigeração de $5 \pm 2{ }^{\circ} \mathrm{C}$ e umidade relativa (UR) de $70 \pm 2 \%$, e pesados em balança analítica nos dias 1, 4, 7, 10, 13, 16, 19, 22 e 25 para cálculo de perda de massa. ${ }^{11}$

Determinação dos teores de sólidos solúveis totais (SST) e acidez. total titulável (ATT)

Para a determinação de SST e ATT das uvas, foram avaliadas apenas uvas com o filme que apresentou os melhores resultados na perda de massa. Desta forma, os cachos das uvas foram cobertas com o filme do amido acetilado e, posteriormente, armazenados 
sob refrigeração de $5 \pm 2{ }^{\circ} \mathrm{C}$ e UR de $70 \pm 2 \%$ por 16 dias, sendo que para cada dia $(1,4,10,13$ e 16) foram retirados 3 cachos com filmes e 3 cachos do controle (sem filme) para análise. O suco foi obtido triturando-se e filtrando as amostras. As análises de SST foram realizadas em triplicata com o auxílio de um refratômetro portátil (Quimib Isso 9002 Q-109B). Os resultados foram expressos em graus brix $\left({ }^{\circ} \mathrm{B}\right){ }^{30}$ As análises de ATT foram realizadas por titulometria de neutralização, utilizando-se $10 \mathrm{~mL}$ de suco de uva. A titulação foi realizada utilizando hidróxido de sódio $0,1 \mathrm{~mol} \mathrm{~L}^{-1}$ e 3 gotas de fenolftaleína a $1 \%$, como indicador. Os resultados foram expressos em porcentagem (\%) de ácido tartárico por $100 \mathrm{~g}$ do fruto. ${ }^{30}$

Também foi determinada a relação de (SST/ATT) com o intuito de verificar a taxa de maturação do fruto. ${ }^{30}$

\section{Análise estatística}

A análise estatística para comparação dos resultados expressos em médias \pm erro padrão de médias, obtidos para as amostras de filmes foi realizada utilizando ANOVA com teste Tuke $\mathrm{p}<0,05$. Todas as análises estatísticas foram realizadas utilizando o software Biostat.

\section{RESULTADOS E DISCUSSÃO}

\section{Propriedades dos filmes}

A espessura dos filmes foi de $0,010 \mathrm{~mm}$ para OXAC, ET, AC, NAT a 0,027 $\mathrm{mm}$ para OX, conforme dados apresentados na Tabela 1. Esses resultados foram inferiores em comparação com trabalho apresentado na literatura, ${ }^{11}$ onde o valor foi de $0,053 \mathrm{~mm}$ para o filme de gelatina com amido de trigo. A espessura é um parâmetro que influencia as propriedades dos filmes e quando controlada permite a uniformidade do material e a validade das comparações entre suas propriedades. ${ }^{31}$

Tabela 1. Espessura, solubilidade em água, opacidade e perda de massa em uvas cobertas com os filmes compostos de gelatina, sorbitol e amidos de mandioca modificados: amido cationico (CAT), oxidado (OX), oxidado e acetilado (OXAC), eterificado (ET), acetilado (AC) e nativo (NAT)

\begin{tabular}{lccc}
\hline Filmes & $\begin{array}{c}\text { Espessura } \\
(\mathrm{mm})\end{array}$ & $\begin{array}{c}\text { Solubilidade em água } \\
(\%)\end{array}$ & $\begin{array}{c}\text { Opacidade } \\
(\%)\end{array}$ \\
\hline CAT & $0,014 \pm 0,004^{\mathrm{a}}$ & $30 \pm 3,70^{\mathrm{a}}$ & $54 \pm 3,30^{\mathrm{a}}$ \\
OX & $0,027 \pm 0,001^{\mathrm{b}}$ & $44 \pm 28,15^{\mathrm{a}}$ & $74 \pm 2,05^{\mathrm{b}}$ \\
OXAC & $0,010 \pm 0,002^{\mathrm{b}}$ & $28 \pm 15,99^{\mathrm{a}}$ & $42 \pm 2,80^{\mathrm{c}}$ \\
ET & $0,010 \pm 0,001^{\mathrm{b}}$ & $100 \pm 0,01^{\mathrm{b}}$ & $54 \pm 2,70^{\mathrm{a}}$ \\
AC & $0,010 \pm 0,001^{\mathrm{b}}$ & $36 \pm 3,71^{\mathrm{a}}$ & $69 \pm 2,70^{\mathrm{d}}$ \\
NAT & $0,010 \pm 0,001^{\mathrm{b}}$ & $55 \pm 1,93^{\mathrm{c}}$ & $62 \pm 1,30^{\mathrm{e}}$ \\
\hline
\end{tabular}

Médias com letras iguais na mesma coluna não diferem ao nível de $\mathrm{p} \leq 0,05$.

A solubilidade em água dos filmes variou de $28 \%$ para OXAC a $100 \%$ para ET (Tabela 1). O menor valor para os filmes estudados foi superior aos encontrados na literatura para o filme de gelatina e amido de trigo $(24,38 \%),{ }^{11}$ como também para o filme composto por gelatina em um $\mathrm{pH}$ de $5,5(19,77 \%) .{ }^{32}$

A solubilidade é um fator que direciona a aplicação do filme como embalagem de produtos alimentícios. ${ }^{11}$ Assim, em alguns casos, como nos produtos semiprontos, destinados ao preparo sob cozimento, a total solubilização em água pode ser benéfica. Entretanto, quando o alimento exsuda uma solução aquosa, filmes de elevada solubilidade não são indicados. Desta forma, para frutas como a uva, deve-se optar por filmes que possuam solubilidade moderada, pois a mesma não possui liberação de exsudado, além de facilitar a retirada do filme para o consumo, como é o caso dos amidos de mandioca modificados, com exceção do eterificado que possui uma alta solubilidade.

Pode-se observar na Tabela 1 que os filmes OX e OXAC apresentaram desvios padrão superiores aos demais filmes, no que se refere à solubilidade em água. Isso é uma evidência de que a reação de oxidação resulta em heterogeneidade das amostras. Após a acetilação dos amidos oxidados essa heterogeneidade diminui e, consequentemente, o desvio padrão.

As opacidades apresentaram diferenças significativas entre os filmes, sendo que o filme mais opaco apresentou 74\% (OX) e o menos $42 \%$ (OXAC), como pode ser visto na Tabela 1. Esses valores são maiores quando comparados com os dados da literatura, que apresentam $40 \%$ para o filme de gelatina e amido de sorgo e $10 \%$ para o filme de gelatina e amido de trigo, ${ }^{11}$ como também em relação aos filmes compostos por gelatina, triacetina e ácido caproico, a opacidade foi de $14,51 \% .{ }^{5}$ Portanto, a utilização dos amidos de mandioca modificados promoveu uma menor transparência dos filmes, porém, visualmente não causam alterações significativas na visibilidade após sua aplicação na fruta. A opacidade pode variar em função do teor de amilose dos amidos, pois suas moléculas em solução, devido à linearidade, tendem a se orientar paralelamente, aproximando-se o suficiente para se formar ligações de hidrogênio entre hidroxilas de cadeias adjacentes. Como resultado, a afinidade do polímero por água é reduzida, favorecendo a formação de pastas mais opacas, porém com maior resistência. ${ }^{11}$

As temperaturas de transição vítrea (Tg), obtidas utilizando a calorimetria exploratória diferencial (DSC), apresentaram valores semelhantes para todos os filmes $\left(-12^{\circ} \mathrm{C}\right)$, como observado na Figura 1. Esses resultados indicam que após a inserção de sorbitol nos filmes, esses se tornaram mais maleáveis, pois os valores de $\mathrm{Tg}$ para o amido sem plastificação são próximos de $50{ }^{\circ} \mathrm{C} .{ }^{33} \mathrm{Assim}$, essa maleabilidade dos filmes garante uma melhor cobertura nas frutas, além de evitar possíveis rachaduras na película. Desta forma, pode-se armazenar este produto até aproximadamente $-12{ }^{\circ} \mathrm{C}$ que o filme ainda manterá a sua flexibilidade, assim poderia acondicionar o fruto com o filme em condições de baixa temperatura, promovendo um aumento da vida útil do mesmo.

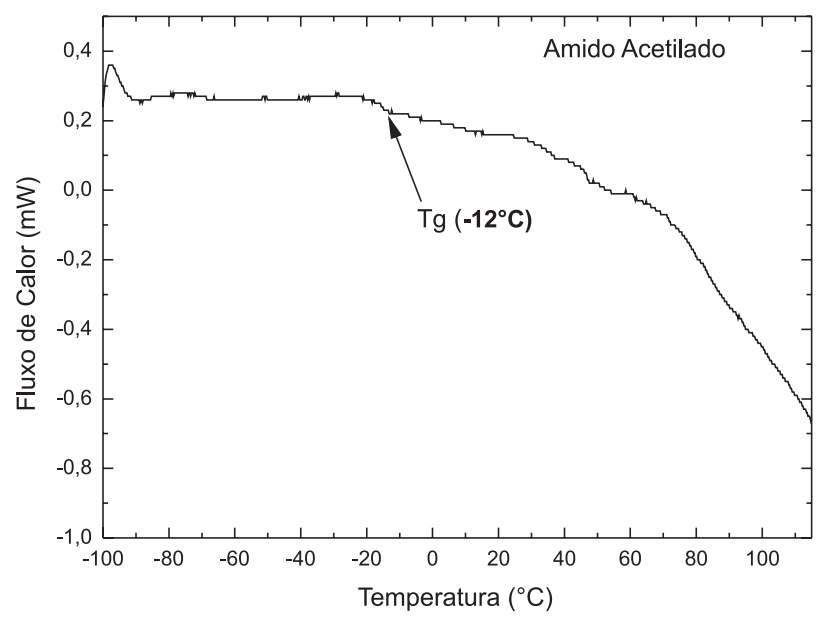

Figura 1. Curva de DSC para o filme de amido acetilado com gelatina e sorbitol

As temperaturas de degradação dos diferentes filmes foram obtidas utilizando o TGA. Constatou-se que essas não possuem diferença significativa, pois ficaram próximas de $250^{\circ} \mathrm{C}$. Portanto, as modificações realizadas no amido não alteraram a sua estabilidade térmica. Também se constatou que os filmes possuem uma perda de 


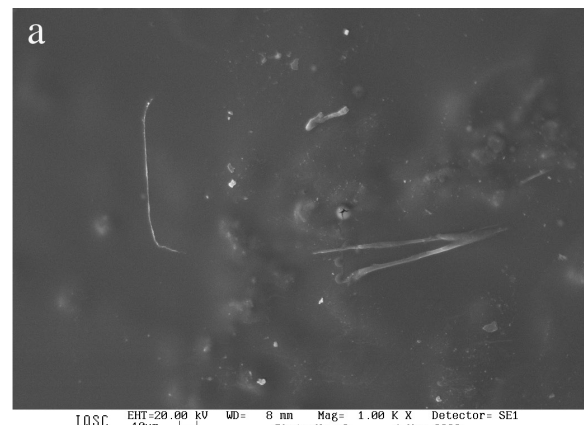

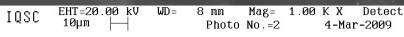

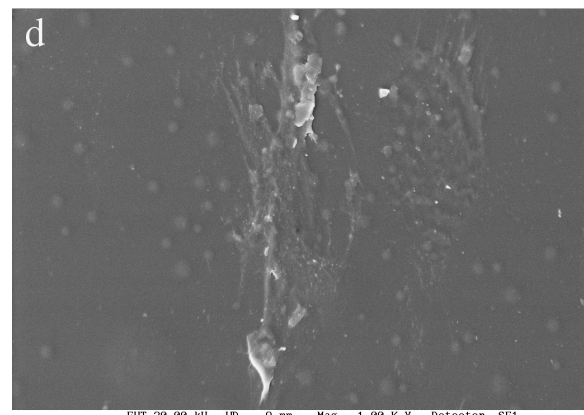

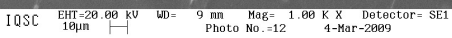
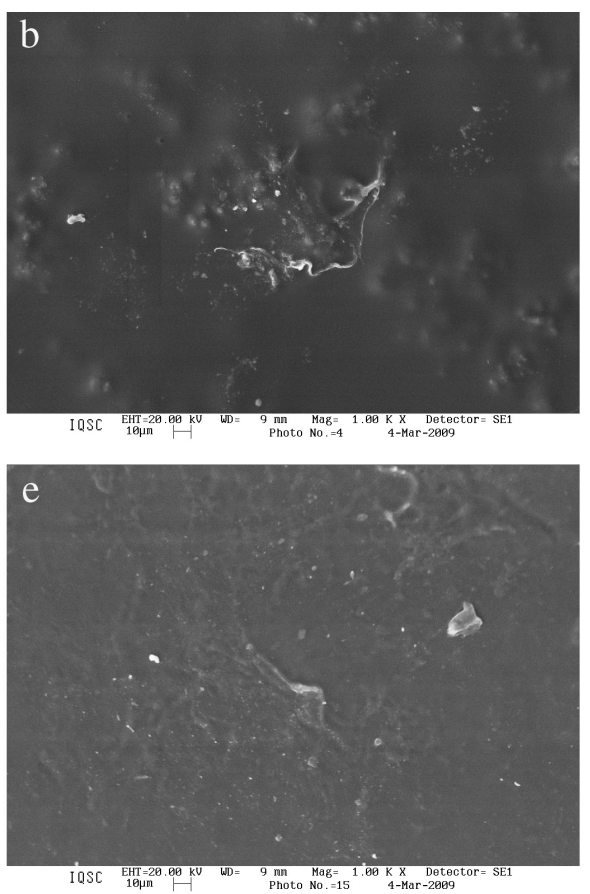
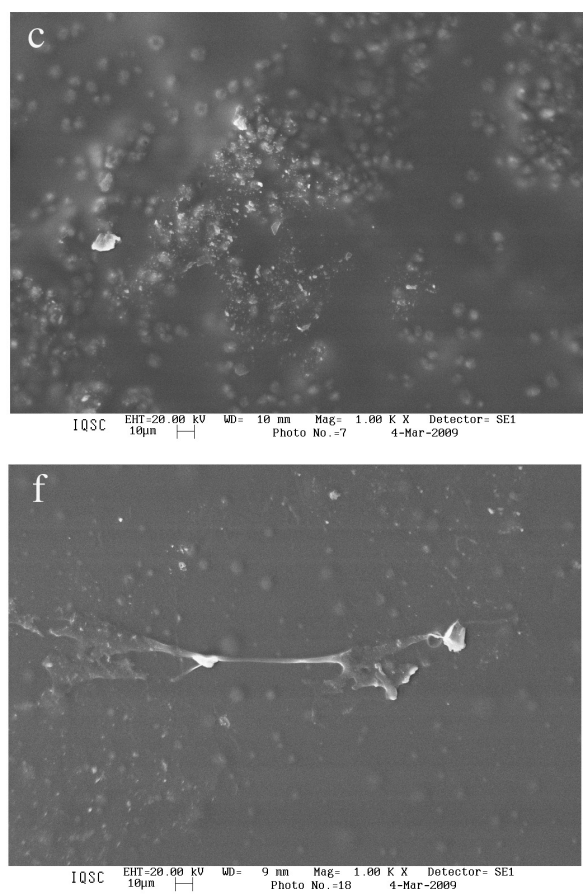

Figura 2. Diferenças nas superfícies, em relação às rugosidades, dos filmes de gelatina/sorbitol/amidos de mandioca: a- acetilado; b- nativo; c- oxidado; $d$ - oxidado acetilado; e-cationico e f-eterificado, apresentadas pelas micrografias com ampliação de $1000 X$

água de aproximadamente $3,5 \%$, entre 25 até $100{ }^{\circ} \mathrm{C}$, sendo que não houve diferenças significativas entre os diferentes amidos estudados.

Com a finalidade de se observar e analisar possíveis rugosidades e imperfeições foram realizadas medidas de MEV. Na Figura 2, podemse observar as micrografias para os diferentes filmes de amido de mandioca com gelatina e sorbitol. Nota-se que as amostras a, $d$, e e f possuem uma maior compatibilidade entre as substâncias, tornando-se filmes mais homogêneos, ou seja, com menos rugosidade. Entretanto, as amostras b e c são filmes que, possivelmente, não apresentaram uma boa interação entre amido/gelatina/sorbitol, pois mostram na sua superfície certa rugosidade, que possivelmente ocorreu devido a uma exsudação das substâncias, o que não é de grande interesse para obtenção de um filme que tenha boas propriedades de barreira. Os filmes que apresentaram maior homogeneidade foram acetilado, oxidado acetilado, catiônico e eterificado, tornando-se possíveis candidatos para a cobertura de frutas.

\section{Aplicação dos filmes}

As uvas receberam coberturas dos diferentes tipos de filmes, com o objetivo de se avaliar a perda de massa. Esta ocorre principalmente com a perda de água, ou seja, quanto maior a perda de massa, maior a passagem de vapor d'água. No entanto, também pode ocorrer perda de substâncias voláteis. Esses fatores podem levar principalmente ao murchamento das frutas, ${ }^{14}$ podendo acarretar em perda do seu odor característico. A redução na perda de massa pode promover um possível aumento da vida de prateleira das frutas.

Na Figura 3, estão apresentadas as perdas de massas em função dos dias de armazenamento. Nota-se que o controle apresentou a maior perda de massa ao longo do tempo, chegando ao final com uma média de $14,10 \%$, valor bem superior ao encontrado para as uvas cobertas pelo filme AC, que teve uma média de 7,46\%. Após 25 dias de armazenamento, ao comparar os valores de perda de massa do fruto recoberto com o filme AC em relação ao controle, observou-se que este perdeu a mesma quantidade de massa que em apenas 13 dias, o que indica que as uvas com o filme $\mathrm{AC}$ possivelmente aumentaram a vida de prateleira em até 12 dias. Além disso, após este período estas frutas permaneceram visualmente com aspecto agradável e próprio para o consumo.

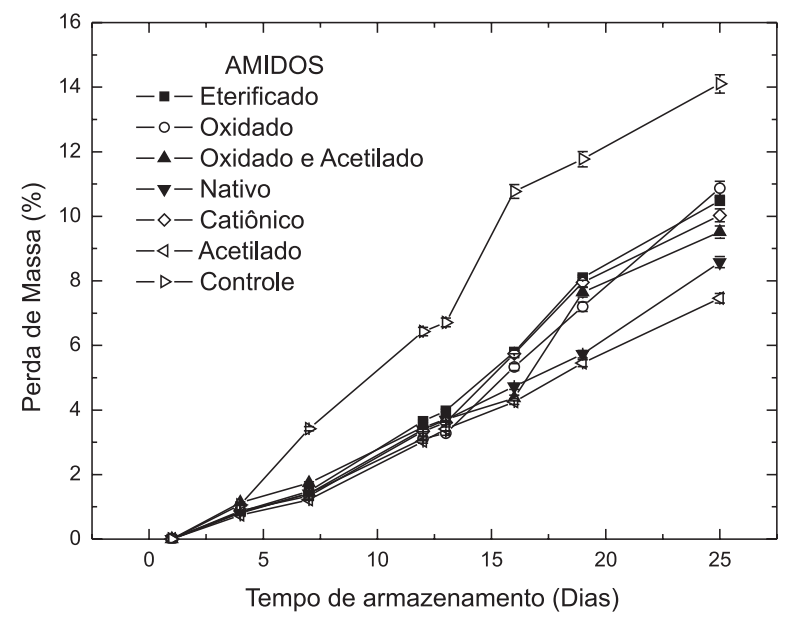

Figura 3. Perda de massa de uvas 'Benitaka', sem cobertura (controle) e recobertas com filmes utilizando diferentes amidos, em função do tempo de armazenamento sob refrigeração $\left(5^{\circ} \mathrm{C}\right)$. Cada símbolo representa o valor médio de 3 repetições

Dentre os filmes analisados, a maior perda de massa foi constatada para as uvas cobertas com filme OX (aproximadamente $10,87 \%$ ), sendo que o tratamento controle apresentou esta perda de massa no $16^{\circ}$ dia de armazenamento, resultando no aumento da vida útil em 9 dias. Isto corrobora as microscopias (Figura 3), pois esse filme apresentou menor homogeneidade quando comparado com o acetilado, que foi um dos mais homogêneos, garantindo um melhor recobrimento da fruta.

Ao comparar as curvas do filme preparado com amido nativo e com amido acetilado (melhor resultado), verificaram-se comporta- 
mentos bem similares. A diferença entre eles atinge $1 \%$ apenas no período de 25 dias. Dessa forma, seria vantajoso acetilar o amido apenas para períodos superiores a 25 dias, quando a diferença entre essas coberturas aumentou significativamente.

Em experimentos apresentados na literatura com filmes recobrindo as uvas 'Crimson', o tratamento controle apresentou semelhança com o resultado obtido neste trabalho. Entretanto, as uvas com filme utilizadas naquele experimento tiveram resultados inferiores, pois se obteve um aumento de vida útil de 10 dias. ${ }^{11}$ Assim, a diferença verificada entre os resultados devem ser atribuídas ao tipo de amido e sua modificação e à espessura dos filmes. A espessura dos filmes é inversamente proporcional à difusão de vapor de água e outras substâncias voláteis. Desta forma, quanto maior a espessura, menor a perda de massa (vapor de água). No entanto, os filmes apresentados na literatura, ${ }^{11}$ apesar de mais espessos, mostraram maior perda de massa em comparação aos obtidos nesse trabalho. Portanto, a diferença estaria na composição química e estrutural dos filmes.

Para cobertura de pimentões utilizando filmes de fécula de mandioca na concentração de $5 \%$, os resultados obtidos não foram promissores. Foi observado um aumento de perda de massa nos pimentões armazenados sobre refrigeração de aproximadamente $15,93 \%$, entretanto, para o controle a perda foi de $11,99 \%$, ou seja, não se constatou nenhum benefício. ${ }^{14}$ Portanto, os resultados obtidos neste trabalho com os amidos modificados associados à gelatina $\mathrm{e}$ sorbitol foram promissores no que se refere à perda de massa em uvas.

De acordo com os dados obtidos da Figura 3, apenas o amido acetilado apresentou uma menor perda de massa em comparação ao amido nativo. Todas as outras modificações não apresentaram vantagem. Por esse motivo a continuidade do estudo ocorreu com o amido acetilado. Desta forma, realizaram-se análises de sólidos solúveis totais e acidez total titulável na uva revestida com este filme, para avaliar as propriedades da fruta em função do tempo.

\section{Sólidos solúveis totais (SST)}

Os SST são em sua maioria açúcares que tendem a aumentar com o amadurecimento, devido à maior degradação ou biossíntese de polissacarídeos e/ou em decorrência da perda de umidade, ocorrendo um acúmulo de açúcares nos tecidos. ${ }^{14}$

Notou-se um aumento de SST em função dos dias de armazenamento, tanto para o controle quanto para a uva com o filme. Entretanto, constatou-se que os valores apresentados de SST para a uva recoberta com o filme $\mathrm{AC}$ foram menores significativamente quando comparados com as uvas controle (Tabela 2).

Em uvas maduras, o aumento em SST é geralmente relacionado à perda de água, sem mudanças no peso dos solutos por baga, embora possa estar associado também a uma perda de solutos decorrente da atividade respiratória, do transporte de solutos, da transpiração ou do transporte de água para outras partes da planta. ${ }^{34}$ Desta forma, os resultados indicam que na uva controle pode ter ocorrido maior amadurecimento das frutas ou ainda, maior perda de água, provocando acúmulo de açúcares nas mesmas. Esses resultados corroboram com o gráfico de perda de massa (Figura 3), dando indícios que os valores são referentes à perda de água nas uvas, preconizando que o filme está inibindo o amadurecimento e/ou a perda de água da uva e, consequentemente, aumentando o tempo de prateleira da mesma.

No grupo controle houve um aumento de SST (até 16\%), enquanto no grupo de uvas com o filme não se notou grandes variações. $\mathrm{O}$ mesmo comportamento foi observado em estudos com pepino japonês com fécula de mandioca a $2 \%,{ }^{35}$ como também em coberturas de amido de mandioca a 1, 2, 3 e $4 \%$ em acerola. ${ }^{36}$ Todavia, este fato não foi constatado, no revestimento de pimentões com fécula de mandioca, não se obtendo resultado satisfatório. ${ }^{37}$

\section{Acidez total titulável (ATT)}

Os resultados obtidos para a ATT das uvas com filme acetilado durante o armazenamento não apresentaram diferenças significativas quando comparados com o controle (Tabela 2). Não ocorreu um aumento da acidez, tanto para a uva controle quanto para a recoberta com o filme AC, indicando que o filme não acelerou o amadurecimento do fruto.

A concentração de ácidos orgânicos usualmente declina em decorrência de sua utilização como substrato na respiração ou da sua transformação em açúcares. ${ }^{38}$ Desse modo, as transformações variam de acordo com as condições de armazenamento e possuem um papel importante nas características de sabor e do aroma. ${ }^{39}$ Portanto, podese notar que tanto para a uva recoberta com o filme quanto para o controle não ocorreram grandes mudanças em relação à acidez da fruta, indicando que o filme não favoreceu o amadurecimento do fruto.

A acidez das uvas pode apresentar grandes variações em função das condições de cultivo e do tipo de uva. ${ }^{40}$ Estudo apresentado na literatura analisando 13 tipos diferentes de uva obteve uma variação de 0,55 a $0,91 \%$ nas análises de acidez total titulável. ${ }^{41}$

\section{Relação SST/ATT}

A relação SST/ATT teve um aumento de acordo com o período estudado nas uvas controle e também com filme (Tabela 2), no entanto, constatou-se que para as uvas recobertas com o filme este aumento foi inferior ao controle. Esses resultados indicam que o aumento nos SST ocorre devido à perda de água e não ao amadurecimento das

Tabela 2. Sólidos solúveis totais, acidez total titulável e relação SST/AAT das uvas com filme acetilado

\begin{tabular}{|c|c|c|c|c|}
\hline \multicolumn{5}{|c|}{ Armazenamento (dias) } \\
\hline \multicolumn{5}{|c|}{ Sólidos solúveis totais $\left({ }^{\circ} \mathrm{B}\right)$} \\
\hline & $01^{\circ}$ & $10^{\circ}$ & $13^{\circ}$ & $16^{\circ}$ \\
\hline Filme & $9,15 \pm 0,10^{\mathrm{a}}$ & $11,05 \pm 0,05^{\mathrm{b}}$ & $11,45 \pm 0,05^{\mathrm{d}}$ & $12,15 \pm 0,05^{\mathrm{f}}$ \\
\hline Controle & $9,05 \pm 0,05^{\mathrm{a}}$ & $12,05 \pm 0,05^{\mathrm{c}}$ & $13,45 \pm 0,05^{\mathrm{e}}$ & $16,05 \pm 0,05^{\mathrm{g}}$ \\
\hline \multicolumn{5}{|c|}{ Acidez total titulável (\% ácido tartárico) } \\
\hline Filme & $0,423 \pm 0,006^{\mathrm{a}}$ & $0,426 \pm 0,003^{a}$ & $0,436 \pm 0,010^{\mathrm{a}}$ & $0,430 \pm 0,015^{\mathrm{a}}$ \\
\hline Controle & $0,417 \pm 0,013^{\mathrm{a}}$ & $0,431 \pm 0,012^{\mathrm{a}}$ & $0,433 \pm 0,015^{\mathrm{a}}$ & $0,423 \pm 0,014^{\mathrm{a}}$ \\
\hline \multicolumn{5}{|c|}{ Relação SST/ATT } \\
\hline Filme & $21,63 \pm 0,30^{\mathrm{a}}$ & $25,94 \pm 0,10^{\mathrm{b}}$ & $26,26 \pm 0,11^{\mathrm{d}}$ & $28,25 \pm 0,11^{\mathrm{f}}$ \\
\hline Controle & $21,70 \pm 0,15^{\mathrm{a}}$ & $27,95 \pm 0,12^{\mathrm{c}}$ & $31,06 \pm 0,10^{\mathrm{e}}$ & $37,94 \pm 0,12^{\mathrm{g}}$ \\
\hline
\end{tabular}

Médias com letras iguais na mesma coluna e linha não diferem ao nível de $\mathrm{p} \leq 0,05$. 
uvas, ou seja, o filme mostrou-se promissor para prolongar o tempo de prateleira das mesmas, mantendo as suas propriedades.

\section{CONCLUSÃO}

Os filmes apresentaram baixos valores de espessuras. Entretanto, os filmes obtiveram maiores solubilidade e opacidade comparadas com outros já estudados. Constatou-se que os filmes de amido acetilado, oxidado acetilado, catiônico e eterificado apresentaram maior homogeneidade na superfície, sendo indicados para cobertura de frutos.

$\mathrm{O}$ filme composto pelo amido acetilado apresentou melhores propriedades de barreira, mostrando-se eficiente para cobertura em uvas 'Benitaka', por aumentar a vida de prateleira das uvas em 12 dias. Além disso, promoveu uma diminuição da perda de sólidos solúveis não alterando a acidez titulável, indicando assim que não ocorreu um amadurecimento dos frutos, mas sim diminuiu a perda de água, prolongando o seu tempo de armazenamento.

Apesar de apresentar o melhor resultado de perda de massa, a modificação do amido nativo para amido acetilado seria vantajosa apenas para períodos de armazenamento superiores a 25 dias, onde a diferença entre os filmes aumentou significativamente.

Desta forma, a utilização de filmes biodegradáveis é considerada uma nova opção para o armazenamento de uvas, pois além de diminuir as perdas, também evita a utilização de embalagens não biodegradáveis, que são prejudiciais ao meio ambiente.

\section{AGRADECIMENTOS}

À Fundação Araucária pela concessão da bolsa de iniciação científica (PEBIC) e à Universidade Paranaense - UNIPAR pelo apoio financeiro.

\section{REFERÊNCIAS}

1. http://sistemasdeproducao.cnptia.embrapa.br/FontesHTML/Uva/ CultivodaVideira/cultivares.htm, acessada em Julho 2010.

2. Freitas, A. A.; Francelin, M. F.; Hirata, G. F.; Clemente, E.; Schmidt, F. L.; Ciênc. Tecnol. Aliment. 2008, 28, 172.

3. Neves, L. C.; Silva, V. X.; Benedette, R. M.; Prill, M. A. S.; Vieites, R. L.; Roberto, S. R.; Rev. Bras. Frutic. 2008, 30, 65.

4. Castro, J. V.; Park, K. J.; Honório, S. L.; Rev. Bras. Eng. Agríc. Ambient. 1999, $3,35$.

5. Davanço, T.; Tanada-Palmu, P.; Grosso, C.; Ciênc. Tecnol. Aliment. 2007, 27, 408.

6. Oliveira, A. F.; Soldi, V.; Quim. Nova 2009, 32, 1845.

7. Laranjeira, M. C. M.; Fávere, V. T.; Quim. Nova 2009, 32, 672.

8. Ferreira, V. F.; Rocha, D. R.; Silva, F. C.; Quim. Nova 2009, 32, 623.

9. Liporacci, J. S. N.; Mali, S.; Grossmann, M. V. E.; Semina: Ciênc. Agrária 2005, 26, 345.

10. Batista, J. A.; Tanada-Palmu, P. S.; Passos, F. A.; Trani, P. E.; Grosso, C. R. F.; Hortic. Bras. 2005, 23, 841.

11. Fakhouri, F. M.; Fontes, L. C. B.; Gonçalves, P. V. M.; Milanez, C. R.; Steel C. J.; Collares-Queiroz, F. P.; Ciênc. Tecnol. Aliment. 2007, 7, 369.

12. Janjarasskul, T.; Krochta, J. M.; Annu. Rev. Food Sci. Technol. 2010, 1, 415.
13. Kang, H. J.; Sea, C. M.; Food Sci. Technol. 2010, 43, 903.

14. Lemos, O. L.; Rebouças, T. N. H.; São José, A. R.; Vila, M. T. R.; Silva, K. S.; Bragantia 2007, 66, 693.

15. Thakhie, W.; Devahastin, W.; Soponronnarit, S.; J. Food Eng. 2010, 99 , 216.

16. Kokoszka, S.; Debeaufort, F.; Hambleton, A.; Lenart A.; Voilley, A.; Innov. Food Sci. Emer. Technol. 2010, 11, 503.

17. Silva, W. A.; Pereira, J.; Carvalho, C. W. P.; Ferrua, F. Q.; Ciênc. Agrotecnol. 2007, 31, 154.

18. Parra, D. F.; Tadini, C. C.; Ponce P.; Lugão A. B.; Carbohydr. Polym. 2004, 58, 475.

19. Larotonda, F. D. S.; Matsui, K. N.; Soldi, V.; Laurindo, J. B.; Braz. Arch. Biol. Technol. 2004, 47, 477.

20. Bobbio, F. O.; Bobbio, P. A.; Introdução à Química de Alimentos, $3^{\mathrm{a}}$ ed., Varela: São Paulo, 2003.

21. Arvanttoyannis, I. S.; Nakayama, A.; Aiba, S. I.; Carbohydr. Polym. 1998, 37, 371.

22. Poppe, J. Em Gelatin Thickening and Gelling Agents for Food; Imeson A., ed.; Blackie Academic \& Professional: New York, 1997, chap. 7.

23. Carvalho, R. A.; Grosso, C. R. F.; Ciênc. Tecnol. Aliment. 2006, 26, 495.

24. Moraes, I. C.; Silva, G. G. D.; Carvalho, R. A.; Habitante, A. M. Q. B.; Bergo, P. V. A.; Sobral, P. J. A.; Ciênc. Tecnol. Aliment. 2008, 28, 738.

25. Kokoszka, S.; Debeaufort, F.; Lenart, A.; Voilley, A.; Int. Dairy J. 2010, $20,53$.

26. Baruffaldi, R.; Oliveira, M. N.; Fundamentos de Tecnologia de Alimentos, $3^{\text {a }}$ ed., Atheneu: São Paulo, 1998.

27. Bergo, P.; Sobral, P. J. A.; Prison, J. M.; J. Food Process. Preserv. 2010, $34,401$.

28. Khwaldia, K.; Arab-Tehrany, E.; Desobry, S.; Comprehensive Rev. Food Sci. Food Saf. 2010, 9, 82.

29. Abdorreza, M. N.; Cheng, L. H.; Karim, A. A.; Food Hydrocolloids 2011, 25, 56.

30. Bolzan, R. P.; Dissertação de Mestrado, Universidade Federal do Paraná, Brasil, 2008.

31. Henrique, C. M.; Cereda, M. P.; Sarmento, S. B. S.; Ciênc. Tecnol. Aliment. 2008, 28, 231.

32. Ferreira, A. H.; Dissertação de Mestrado, Universidade Estadual de Campinas, Brasil, 2006.

33. Dragunski, D. C.; Pawlicka, A.; Mol. Cryst. Liq. Cryst. 2002, 374, 561.

34. Coombe, B. G.; Am. J. Enol. Viticult. 1992, 43, 101.

35. Reis, K. C.; Elias, H. H. S.; Lima, L. C. O.; Silva, J. D.; Pereira, J.; Ciênc. Agrotec. 2006, 30, 487.

36. Maciel, M. I. S.; Lima, V. L. A. G.; Santos, E. S.; Lima, M. S.; Rev. Bras. Frutic. 2004, 26, 168.

37. Vicentini, N. M.; Castro, T. M. R.; Cereda, M. P.; Ciênc. Tecnol. Aliment. 1999, 19, 127.

38. Ferreira, S. M. R.; Freitas, R. J. S.; Larazzi, E. N.; Ciênc. Rural 2004, 34, 329.

39. Chitarra, M. I. F.; Chitarra, A. B.; Pós-colheita de frutas e hortaliças: Fisiologia e Manuseio, 2a ed., UFLA: Lavras, 2005.

40. Botelho, R. V.; Pires, E. J. P.; Terra, M. M.; Carvalho, R. L.; Rev. Bras. Frutic. 2003, 25, 96.

41. Leão, P. C. S.; Rev. Bras. Frutic. 2002, 24, 734. 